\title{
A Digital Circular Economy for SDG 11 and SDG 12
}

\author{
Kannikar Khaw-ngern ${ }^{1}$, Prateep Peuchthonglang ${ }^{2}$, Lampong Klomkul ${ }^{3}$, Chainarong Khaw-ngern ${ }^{4}$ \\ ${ }^{1}$ Faculty of Buddhism, Mahachulalongkornrajavidyalaya University, \\ ${ }^{2}$ Faculty of Business Administration and Liberal Arts, Rajamangala University of Technology Lanna, \\ ${ }^{3}$ Faculty of Education, Mahachulalongkornrajavidyalaya University, \\ ${ }^{4}$ Faculty of Humanities, Mahachulalongkornrajavidyalaya University \\ ${ }^{1}$ kannikar.khaw@gmail.com, ${ }^{2}$ Khun_Jedrin@ hotmail.com, ${ }^{3}$ research.mcu@gmail.com, ${ }^{4}$ chainarong.kha@mcu.ac.th
}

\begin{abstract}
Due to the population growth, cities and metropolitan areas contribute about $60 \%$ of global GDP, but they generate about $70 \%$ of global carbon emissions and account for over $60 \%$ of resource use and increasing urban energy consumption and pollution. Worldwide consumption and production also increase the use of the natural environment and resources in a way that continues to have destructive impacts on the planet. This article is to study the Sustainable Development Goal 11: Sustainable Cities and Communities and Goal 12: Sustainable Consumption and Production, to study the role of digital technology and digital transformation in Circular Economy, and to investigate how digital based applications can contribute to sustainable cities and communities. Documentary study and literature review were used for data collection. Moving towards circular economy is a challenge due to the lack of connections and accurate information sharing, complication in developing circular business, product, and process models as well as inability to access information and education among consumers. The result shows that digital technologies including big data, analytics, IoT, AI, blockchain, etc. can play a vital role in connecting different sources of information, processing data, providing more access to information, and easing out the complication in designing, production, and service. It can also be used as a tool in managing congestion, risks, and environmental impacts in cities and communities.
\end{abstract}

Keywords

A Digital Circular Economy, SDG 11, SDG 12, Sustainable Cities and Communities

Article Received: 10 August 2020, Revised: 25 October 2020, Accepted: 18 November 2020

\section{Introduction}

The Sustainable Development Goals (SDGs) is the world's best plan to build a better world for people and our planet by 2030. Adopted by all United Nations Member States in 2015, the SDGs are a call to action and to promote prosperity while protecting the environment. The circular economy is a framework for the effective scaling of sustainable economic models within planetary boundaries. The principle of extending the lifecycle for materials is the transition to renewable energy, respect for biodiversity, societal balance and social inclusion. Moving forwards to the circular economy means moving forwards towards the Sustainable Development Goals, which set out on the transition towards a circular economy from various market segments such as agri-food, manufacturing and the built environment.

Technology becomes an important theme in the realm of social innovation, design and coalition-building. Moving towards circular economy is what the world wants to achieve. Thus, digitalization has tools to optimise and streamline the use of resources and processes. The roadmap for a digital circular economy initiative is a good start for the synergies between circular economy and digitalisation. In a digital circular economy, digitalisation has a vital role in making the coordinate and connect material and information flows better via technical solutions such as sensoring, automated platforms, Internet of Things (IoT), or block chain applications. However, many seemingly ordinary digital solutions like apps directly connect to our everyday consumer life, which you can use via your browser or a smartphone app. Implementing circular economy on a large scale cannot be achieved without the help of digital technologies. Big data capabilities, connected objects, deep learning insights, automation and robotization will be at the heart of this transformation. This change will become a new source of value creation for companies and society and give opportunity to new industries to create new jobs. But it requires a profound cultural change to abandon a model that has served and shaped our societies for more than a century. Therefore, It is essential to emphasize the role of digital technologies so that the involving sectors; government, business and industries, research and education, as well as investors will share the same concern and put more effort in accelerate the move towards digital-based circular economy and promote sustainable cities and communities for us and our future generations.

\section{SDG 11: Sustainable Cities And Communities}

Since 2007, more than half the world's population has been living in cities due to urbanisation and the number is expected to rise to $60 \%$ by 2030 . As the powerhouse of economic growth, cities and metropolitan areas contribute about $60 \%$ of global GDP. However, they generate about $70 \%$ of global carbon emissions and account for over $60 \%$ of resource use and increasing urban energy consumption and pollution as well. Cities take up only $3 \%$ of the Earth's land, but they account for 60-80 \% of energy consumption and $70 \%$ of carbon emissions [1].

By 2050, it is estimated that two-thirds of all humanity, 6.5 billion people, will live in urban area. To achieve sustainable development, it is necessary to make changes in the way we build and manage our urban spaces. Cities, 
especially in the developing world, have become dense due to the rising populations and increasing migration and slums are becoming a more significant feature of urban life. These places where we live, work and spend time with our families and friends can determine our common future.

Therefore, cities need to be sustainable for future generations. That means cities will have to provide career and business opportunities, safe and affordable housing, and build resilient societies and economies. Sustainable cities are also healthy and competitive, and able to provide all the societal needs, including food and nutrition, water, and infrastructure, for its people within the capability of the earth. Sustainable cities, thus, requires a circular economy where resources are kept at their highest qualities for as long as possible through sustainable practices such as sharing, remanufacturing, reusing, repairing, and recycling [2].

The transition towards a sustainable city, circular economy, involves collaboration and coordination among the local government, businesses, local organisations, technologies, industries as well as resources. In cities around the world, they have increasingly recognised the diverse benefits of circularity. The lessons and experiences learned by those pioneering cities can provide important insights and can be used as guidance and serve as an action agenda for aspiring circular cities of the future.

Some practical guidelines which have been developed in the Netherlands can be served as an action plan for cities throughout the world in order to create circular cities. Those guidelines include a platform to showcase best practices of the city; finding circular potential of the city and setting priorities and ambitions; calling for business involvement from the start and creating space for experimentation; knowing challenges and addressing solutions; facilitating cross-sectoral collaborations; leading by example and building on success; integrating circular thinking into all educational programs and training; monitoring, adjusting, and scaling [3].

\section{SDG 12: Sustainable Consumption And Production}

SDG 12: "sustainable consumption and production," focuses on promoting resource and energy efficiency, building sustainable infrastructure, and providing more access to green and decent jobs and a better quality of life. The practices are highly relevant to water management, waste management, sustainable products and services, sustainable supply chains as well as synergies with renewable energy on a circularity basis. They can help address problems of water, soil, and air pollution from industries through the circular Rs concept of rethink, reduce, redesign, reuse, repair, refurbish, remanufacture, recycle and repurpose.

It is essential to promote sustainable consumption and production because there is a big jump of material consumption from 2000 to 2010 due to the growth of the middle class in developing countries. The total amount of natural resources used in economic processes increased from $1.2 \mathrm{kgs}$. to $1.3 \mathrm{kgs}$ for each unit of GDP or total 48.7 billion tons to 71.0 billion tonnes respectively, particularly in eastern Asia [4] Consumers have a great impact on the planet which comes in hidden forms. The processes of production and transportation account for $86 \%$ of the impact while they use up $43 \%$ of global energy in producing products, food, services, and so on. Also, another 33\% of energy is lost during the energy generation as generating energy also cost energy. Thus, the circular economy has great potential for energy transition as energy use related to raw materials is a significant part of our energy management. Circular economy practices can also be used in industry and buildings for energy efficiency [5].

\section{Role Of Digital Technology}

Digital technology is made to help people in their tasks. There is still potential for digital technology to be more advanced and more applicable for variety of businesses and industries. In 2019, the global technology market spending reached $\$ 3,360$ billion [6].

Digital technology plays a vital role in making our world more connected with its expanding information network like the Internet and the web. Through it, we can interact and communicate with emails, conference calls, social media apps. The lives of students and teachers are also become better with digitization in the education sector. In the health industry, it has saved thousands of lives with advanced machinery and innovations [7].

Revolution of digital technology has also made a huge change in the labour force as it has been creating new forms and patterns of work which makes others obsolete. For example, 24 million new jobs in energy sector could be created by 2030 as countries around the world make a shift to greener economy and adopt sustainable practices such as using electric vehicles and increasing energy efficiency. Digital technologies, such as AI and data pool are also used for diagnosing and tracking problems in health, agriculture, and the environment sectors [8].

Digital technology provides us better access to information and data and enables us to communicate and work more efficiently. It increases productivity, promotes cost efficiency, preserve information, saves more space, and enhances competitiveness [9]. Besides its benefits in business, digital technology also brings great benefits to industries, such as reducing energy usage, predicting maintenance, increase innovation, and making storage smarter [10]. Therefore, digital technologies (DTs), such as the Internet of Things (IoT), big data, data analytics, and AI are considered essential enablers of the economy and they are applied to circular economy.

\section{Focus On A Digital Circular Economy}

The climate crisis, depletion of natural resources, competition over resources and pollution are affecting Europe and the world more generally, posing a threat to our economy and society. The challenges are manifold and systemic. They are closely linked to economic activities and current lifestyles, unsustainable production and consumption patterns as well as how our economies and societies are structured. It is estimated that at this moment the world is only $8.6 \%$ circular [11]. However, there is a growing recognition amidst politicians, citizens and the industry that changes are dire. Shifting from a linear take-make-dispose model to a circular economy, smarter use of resources, and achieving more sustainable production and consumption 
patterns could bring multiple benefits and help address the multiple challenges listed above.

Maintaining the value of products and materials for as long as possible; minimising resource use and waste; and increasing repair, recovery/reuse of materials and products as well as recycling rates would reduce pressures on resources and decrease greenhouse gas (GHG) emissions. It is estimated that half of the carbon dioxide emitted by the EU's heavy industry by 2050 can be prevented by making the industry more circular [12]. Looking at the global level, $40 \%$ of carbon dioxide emissions from key materials (i.e. cement, steel, plastics, aluminium) almost $50 \%$ from the food sector, $40 \%$ from construction and $70 \%$ from the mobility sector could be reduced if these sectors are made more circular by 2050 [13]. Smarter use of resources would allow Europeans to manage materials better and create more value from their use. Indeed, greater circularity can be seen as the means to future proof resource-intensive industrial sectors while simultaneously enhancing competitiveness and industrial modernisation. It has been estimated that the transition would create new markets, jobs, products and services, boost EU's GDP by $7 \%$ and generate a net economic benefit of $€ 1.8$ trillion by 2030 [14].

The current situation we are facing is that our lives, our livelihood, and our world are being threatened by our economic activities which bring huge environmental challenges of resource shortage and global warming. It is, thus, necessary to examine different approaches to business in order to meet these challenges. It is an urgency for all parties to develop industrial and business models which take less and less on finite, non-renewable resources and reduce carbon emissions. With a great deal of change in industrial revolution, technology has become a key player in redesigning businesses for more ecologically friendly. Digital technology can be used in many forms to map, organise, and optimise our global economy in adapting to a circular economy.

Moving towards a full circular economy is a big challenge, but so was digital transformation at its beginning. It took years and high cost as well as efforts in the journey of digital transformation from IoT to blockchain which now has been used more widely. Therefore, it is the time to push for changes in business models, products and services to move forward towards sustainability in the long term. The transformation should promote big data capabilities, connected objects, deep learning insights and advanced automation. The circular economy will ensure a positive human future which is enabled by technological breakthroughs and intelligent design. Technology will take a critical part in this change and it will make us survive on infinite resources when incorporating innovation into businesses and industries.

The digital transformation is taking place fast. Around $60 \%$ of the global population has access to the Internet. Around two-thirds uses a mobile [15]. Digitalisation is transforming our economies, societies, communications, jobs and necessary skills for today and tomorrow [16]. There is no turning back. The question that remains is whether we will embrace the many possibilities digitalisation generates and create framework conditions which maximise them and minimise unwanted consequences.
In real life, data and digitally-enabled solutions like online platforms, smart devices, artificial intelligence (AI), the Internet of things (IoT) and blockchain are already used to support a transition to a sustainable circular economy. They are used to improve design, production, consumption, reuse, repair, remanufacturing and waste management, including recycling (see Figure 1) [17].

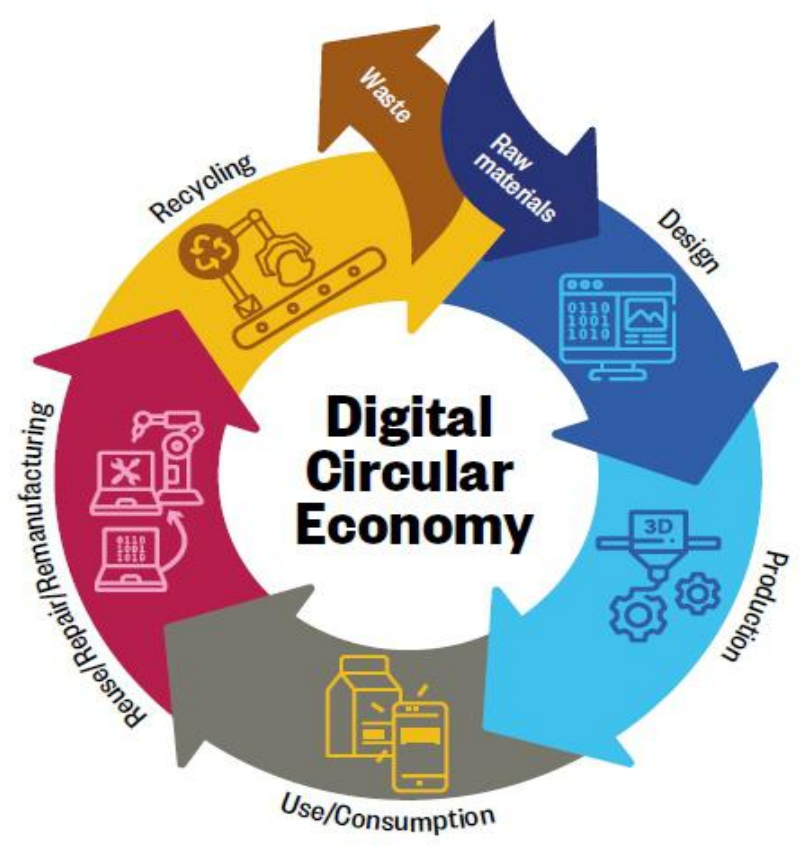

Figure 1. Digitalisation as an enabler for a circular economy [18]

Achieving a sustainable circular economy is one of the most complex challenges of today. Digitalisation cannot immediately solve all of the challenges. However, digitalization can be an enabler and accelerator for positive change and help address many of these obstacles. As digitalisation is designed to address complexities, gearing the use of data and digitally-enabled solutions to address the sustainability crisis offers many possibilities. In the transition to a circular economy, different approaches to using digitalisation have been divided into three categories as below: (see also figure 2) [19]

1) Digitalisation for knowledge improvement, better connections and information sharing. The improvement of data management by improving information and knowledge could raise awareness and guide action for all stakeholders. It also will improve policymaking and the implementation of existing legislation. Digitally-enabled solutions can build strong connections and partnerships among stakeholders, and help information travel with products and materials across the value chains.

2) Digitalisation for making business models, products and processes more circular. Improving the management of data and digital-enabled solutions can lead to greater circularity as it will support more sustainable business models and improve designs, production, use, reuse, repair, and waste management which includes recycling.

3) Digitalisation for strengthening the role of citizens and consumers. Digitalisation can give people more access 
to information and education. It also influences and enable people to make sustainable choices and engage them more in active participation in the economy data and knowledge.

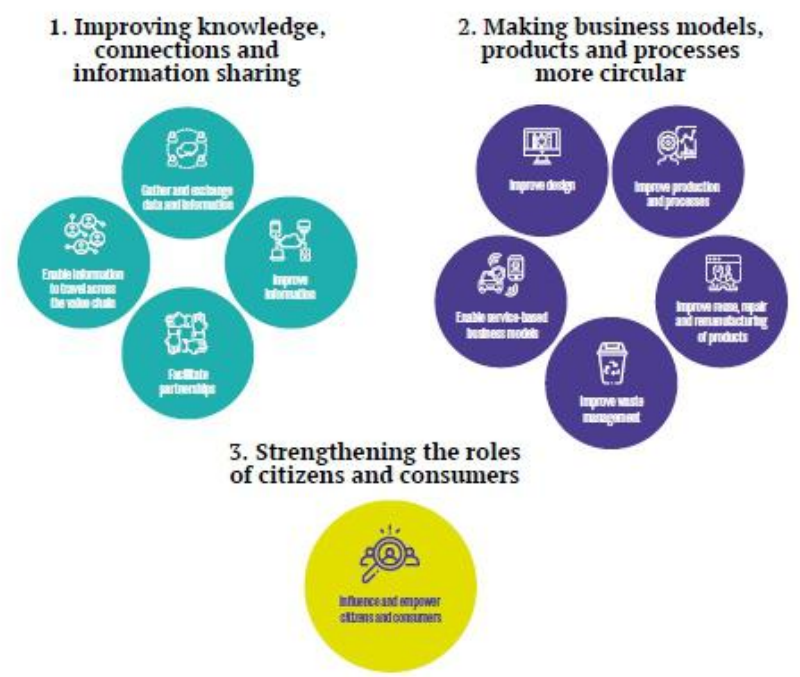

Figure 2. Using digitalisation in the transition to a circular economy [20]

In achieving the circular economy, the whole current value chains need to be redesigned from resource extraction and manufacturing to end of life of products and services. Each participant at each stage needs to get delineated feedback across the entire value chain in order to make change in their attitudes and business models at all stages of the product value chain. At the government and administration sector, it is essential that they take a global perspective of the economic cycle. Digital technology will take important part in mapping, organizing, controlling, and ensuring consistency throughout the chain. At the operation level, this can greatly impact all levels of the product chain as it develops interactions and interdependencies among the manufacturing, distribution, and consumer ecosystems. Thus, it requires a closer look at a potential digital circular economy model to understand the role of technology as enablers for making such changes [21].
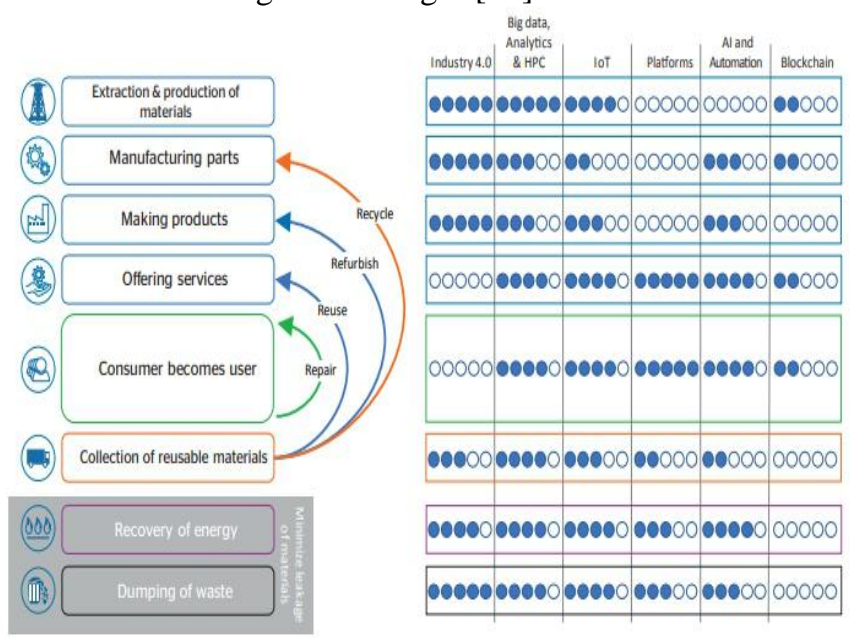

Figure 3. Circular economy digital model (Industry example) [22]
Figure 3 above shows the product lifecycle within the circular economy and how digital technology can be used as digital enablers. The product chain starts with reducing raw material extraction by placing it with green material. Industry 4.0 with $3 \mathrm{D}$ printing can help in reducing and reusing raw material. Next, product needs to be designed to extend the product life and product-as-service model. Big Data, analytics and High Performance Computing (HPC) can be used as support of predictive maintenance models to eliminate malfunction and waste during operation. Data platform and blockchain can connect all parties to a sharing business model for cost effectiveness. To further support the product-as-a service model, design should easy personalization (mass customization versus mass standardization). Furthermore, it should be designed for continual improvement and zero fail service (zero default standard). This may be done through a connected flow, with feedback data to be accustomed improve the planning and efficiency of a product and supply predictive analytics

In order to move from take-make-use-dispose product line to a circular economic system, all involving sections need to have all relevant information about resource used, sourcing and working conditions, production and recycling processes, etc. Digital technology can make this all information updated and easy to access and traceable as well as ensure the information security. This is a complicated task that need to be done by digital means. With this data, it is possible to virtually experience what happens in all phases of the product life cycle and then create a virtual digital product which can be used to study what raw material and processed materials are best suited for the product, production, the use phase, and recycling, so that they can be incorporated into a new lifecycle further down the line. Based on this knowledge, purchasing can decide where to buy the materials, whether from natural sources or recycling. The business also can identify risks to environment, people, and the company and decide whether to minimize or avoid [23].

The most effective solutions will involve a combination of smart consumption and disposal measures as well as the development of cost-competitive and environmentally friendly alternatives. For example, we can implement digital circular solutions for reusing or repurposing plastic waste in the most efficient way. Plastics regeneration technologies such as pyrolysis will also play a part in these efforts and are technologically and financially viable alternatives. However, it also requires a cross-value-chain collaboration to appreciate the full benefits of plastics regeneration. More than 40 global and regional chemical companies, packagers, consumer goods manufacturers, and waste managers have pledged to invest up to $\$ 1.5$ billion in plastic waste management infrastructure in Southeast Asia [24]. This move clearly signals that the private sector is ready to scale up efforts to combat one of the most pressing environmental issues of our times. While this is a credible start that may yet catalyze further investments in the cause, we still have a way to go before we find a comprehensive, definitive solution.

The circular economy powered by digital technologies will play a vital role in achieving SDG 12 by reducing the requirement for extraction of limited natural resources. It can help identify new and alternative manufacturing 
strategies that provide additional value propositions to customers, while reducing structural waste [25]. Also, the productivity and intelligence gained from digital technologies can unlock new solutions to environmental challenges such as climate change, biodiversity, plastic and e-waste, ocean health, water management, and air pollution, among others.

Likewise, digital technologies will be one of contributors to the achievement of SDG 11; Make Cities and Human Settlements Inclusive, Safe, Resilient, and Sustainable. To provide access to safe, affordable, accessible and sustainable transport systems for all by 2030, machine learning algorithms in smart transport can help increase safety and traffic flows [26] and at the urban-level, these capabilities also enable the integration of public and private modes of transport to create an efficient city mobility service by looking for patterns in transport demand, optimizing routes and improving efficiency and safety [27].

To be adaptable to climate change and resilient to disasters, many applications for weather and disaster resilience emphasize on the ability to forecast extreme weather and natural disasters. Predictive analytics powered by AI and other digital technologies including IoT, drones, blockchain, and advanced sensor platforms can help governments and the scientific communities monitor tremors, floods and windstorms, as well as sea level changes and other possible natural disasters, in realtime with thresholds for automated triggers, that enable early evacuations when needed [28].

To reduce the environmental impact of cities and improve air quality, some early examples are filtration, air purifiers which use machine learning to record air quality and environment data in real-time and adapt filtration efficiency [29]. AI applications are also used for real-time air quality monitoring. Besides, the combination of machine learning and IoT is used for harnessing data from air quality stations and more widespread sources, such as traffic systems, weather satellites and stations as well as industrial sector, topographic maps, and even social media, to develop predictive analytics for 2 to 7-10 day forecasts [30]. Machine learning is used to provide real-time data on water quality, while $\mathrm{AI}$ is also used to analyse and determine optimal performance of water and minimize water loss [31]. Digital Technologies can play a vital role in the achievement of the Sustainable Development Goals, SDG 11 and SDG 12 , as it promotes sustainability in natural resource, production and consumption, and waste management throughout the product chain in the business and industrial sector. It also helps promote safe and accessible transport system, resilience to climate change and disaster, clean air and water supply for urban lives. (Figure 4)

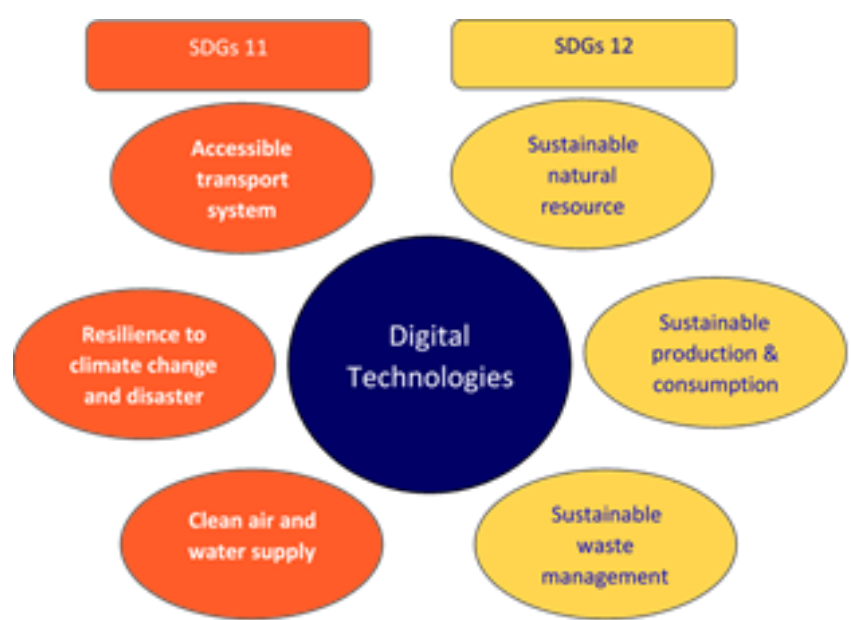

Figure 4. Digital Technology as an Enabler for SDG Goal

\section{Conclusion}

Digital technology is one of good enablers for overcoming many of the factors that are still holding back the circular economy. The development of the circular economy depends heavily on disruptive digital innovations, that is why many pioneering players either already have strong high-tech roots or are creating an ecosystem of partners with key technology capabilities. Also, competition in this fastmoving digital transformation can give more pressure on the formerly cohesive business models, force leaders to reevaluate their value propositions and search for more competitive and comprehensive ways to create value. The end of life of a product means there is value leakage, as important by-products are not collected for productive reuse. Instead of ignoring the value by throwing away products and materials after use, the circular economy stops this practice and recover more value. Digital technologies (DTs), such as the IoT, big data, and data analytics, are considered essential enablers of the circular economy. In a digital circular economy, digitalisation has a vital role in making the coordinate and connect material and information flows better via technical solutions such as Internet of Things (IoT), sensoring, automated platforms, or block chain applications. Consumers can have better access to updated and more interactive information through their smartphones. The emerging application of AI for transition to a circular economy enhance and enable circular economy innovation. However, as both circular and digital technology are emerging fields, there is still little systematic guidance on how digital technologies can be applied to capture the full potential of circular strategies for improving resource efficiency and productivity to the goals of manufacturing companies in contributing the SDG 11 and SDG 12.

Therefore, there should be actions for developing sophisticated national and international governance structures for digital-enabled circular economy. These mechanisms working together with business and industry can ensure sustainable growth that is aligned with UN's Sustainable Development Goals. Besides, investors and capitalists should take part in fund provision to promote digital-based innovations that will advance the digital circular economy as well as promote sustainable cities and communities on cost efficiency. Moreover, further research is also required to identify systematic and repeatable errors 
and to find ways to improve the functioning of AI, specifically for environmental applications.

\section{References}

[1] WEF. (2018) Circular Economy in Cities: Evolving the model for a sustainable urban future. Geneva: WEF.

[2] Kruchten, van S. \& Eijk, van F. (2020) Circular Economy \& SDGs: How circular economy practices help to achieve the Sustainable Development Goals. Amsterdam: The Netherlands Enterprise Agency.

[3] Russell, M. et al. (2019) Circular cities: Holland circular hotspot. Hoofddorp: Holland Circular Hotspot.

[4] Kristoffersena, E. et al. (2020) The smart circular economy: A digital-enabled circular strategies framework for manufacturing companies. Journal of Business Research. 120 (11): 241-261.

[5] "Global technology market spending from 2014 to 2019" https://www.statista.com/statistics/886397/ total-tech-spending-worldwide/

[6] "How Digital Technology Innovations Affect Today's Society”, Mar. 2020 https://businesspartnermagazine. com/how-digital-technology-innovationsaffect-todays-society/

[7] "The Impact of Digital Technologies" https://www.un.org/en/un75/impactdigital-technologies

[8] "10 Advantages of Digitization and Data Capture You Must Know" https://www.aptaracorp.com/blog/10advantages-digitization-and-data-captureyou-must-know

[9] "The Benefits of Digitizing Your Manufacturing Plant" https://www.manufacturing.net/operations/ article/13245983/the-benefits-ofdigitizing-your-manufacturing-plant

[10] European Commission. (2018a) Communication from the Commission to the European Parliament, the Council, the European Economic and Social Committee and the Committee of the Regions on a monitoring framework for the circular economy. Retrieved 28 September 2020 from environment/circularhttps://ec.europa.eu/ economy/pdf/monitoring-framework.pdf

[11] European Commission. (2019a) Communication from the Commission to the European Parliament, the European Council, the Council, the European Economic and Social Committee and the Committee of the Regions: The European Green Deal. Retrieved 28 September 2020 from https://ec.europa.eu/info/sites/ info/files/european-green-dealcommunication_en.pdf

[12] European Commission (2019b), Report from the Commission to the European Parliament, the Council, the European Economic and Social Committee and the Committee of the Regions on the implementation of the Circular Economy Action Plan

[13] GeSI. (2020) A strong and positive link. Retrieved 28 September 2020 from https://digitalaccessindex-sdg. gesi.org/astrong-and-positive-link/

[14] European Commission. (2018b) Towards a swift agreement on a long-term budget for Europe's priorities. Retrieved 28 September 2020 from https://ec.europa.eu/ commission/sites/betapolitical/files/communication_-_longterm_budget_for_europes_priorities.pdf

[15] Hedberg, A. \& Sipka, S. (2020) The Circular economy: Going digital. Brussels: European Policy Centre.

[16] https://wms.flexious.be/editor/plugins/ imagemanager/content/2140/PDF/2020/D RCE_web.pdf

[17] Hedberg, A., Sipka, S. \& Bjerkem, J. (2019) Creating a digital roadmap for a circular economy. Brussels: European Policy Centre.

[18] ATOS. (2019) Circular economy, your digital path: How digital enables the transformation into the sustainable circular economy. 
[19] iPoint. (2020) Towards a Digital Circular Economy. Retrieved 28 September 2020 https://www.ipointsystems.com/solutions/circular-economy/

[20] Rubel, H. et al. (2019) A Circular Solution to Plastic Waste. Boston: BCG Group.

[21] Nexar, viewed December 2017, available at: https://www.getnexar.com/

[22] PwC, Fourth Industrial Revolution for the Earth Harnessing the 4th Industrial Revolution for Sustainable Emerging Cities, November 2017, available at: https://www.pwc.com/gx/en/sustainability/ assets/4ir-for-the-earth.pdf.

[23] "Fourth Industrial Revolution for the Earth: Harnessing Artificial Intelligence for the Earth", January 2018 https://www.pwc.com/gx/en/sustainability/ assets/ai-for-the-earth-jan-

2018.pdf?utm_campaign=sbpwc\&utm_me dium $=$ site\&utm_source $=$ articletext

[24] ARCADYA, Accessed December 2017, Available at http://www.arcadya.io/.

[25] IBM, 2017, Green Horizons, Harnessing the power of cognitive computing and IoT to help fight pollution and climate change, available at: http://www.research.ibm.com/greenhorizons/\#fbid=dQJLQ99TYMS.

[26] Water Planet, Kevin Costner, Water Planet Team Up to Advance Sustainable Water Reuse with Smart Membrane Products, PR Newswire, March 2017, available at: https://www.prnewswire.com/newsreleases/kevin-costner-water-planet-teamup-to-advance-sustainable-waterreusewith-smart-membrane-products300427906.html. 